Received: 12.04 .2016

Accepted: 29.10 .2016

A - Study Design

B - Data Collection

C - Statistical Analysis

D - Data Interpretation

E - Manuscript Preparation

$F$ - Literature Search

G - Funds Collection

DOI:10.5604/17307503.1222842

\section{ChILDREN WITH EPILEPSY: SPECIFIC LEARNING DIFFICULTIES}

\section{Izabela Kaczmarek(A,B,D,E,F,G), Sławomir Jabłoński2(B,D,E,F),} Barbara Steinborn ${ }^{1(B, D, E, F)}$

1 Department and Clinic of Developmental Neurology, Poznan University of Medical Science

2 Institute of Psychology, Adam Mickiewicz University in Poznan

\title{
SUMMARY
}

The problems of children and adolescents with epilepsy pose an important challenge for educational systems around the world. Epilepsy is the most common chronic neurological disease, which occurs in up to $1 \%$ of children and adolescents. The largest incidence of onset is from early childhood to adolescence, therefore, mostly the emotional, cognitive and social problems experienced by patients coincide with the school period. It is commonly believed, as indicated by research, that some of the children and adolescents with epilepsy experience learning difficulties and school problems. This article presents the educational problems of a group of patients in Poland with epilepsy and the co-occurring specific difficulties in the acquisition of scholastic skills like dyslexia, spelling disorder or dyscalculia. The work is a review with an analysis of a case study.

Key words: epilepsy, learning difficulties, dyslexia, school achievements, ICD-10. 
"It should be upheld as an axiom that epileptics require to be educated according to their individual mental capabilities.

No greater mistake is committed in the management of young epileptics than withholding from them the advantages of the mental and physical exercises entailed by educational methods under special supervision and direction."

William Aldner Turner 1907 (Turner, 1907).

\section{INTRODUCTION}

The aim of the present work is to obtain a specification of the situation of Polish children and adolescents with epilepsy, in the case of whom, along with the basic medical diagnosis (neurological disease), there also occur symptoms of so-called specific learning difficulties (SpLDs) (commonly: dyslexia, dyscalculia, dyspraxia, dysorthography, dysgraphia or, in other words, "specific difficulties in acquiring scholastic skills"). The underlying assumption of this work, i.e., describing these disorders in terms of co-occurring phenomena, is in conflict with the manner of approaching this subject commonly acknowledged in Poland. In the regulation of the Minister of National Education from 2010 on ruling about the occurrence of SpLDs we can read the following statement: "Whenever the regulation mentions specific learning difficulties, this term is to be understood as difficulties in learning experienced by students in the intellectual norm, who have problems with acquiring school material due to the specificity of their perceptive, motor and cognitive functioning, not conditioned by neurological diseases" (Dz. U. [Legal Gazette] from 2010, No. 228, item 1491). An interpretation of this regulation as applied in Poland entails serious consequences, especially when it comes to providing educational and therapeutic support for children with symptoms of, for instance, dyslexia or dyscalculia, who at the same time suffer from epilepsy. According to this interpretation, the diagnosis of epilepsy rules out the possibility of a simultaneous diagnosis of SpLDs. Meanwhile, the stance of scientific circles that investigate this problem (see below) and of many practitioners, especially clinical psychologists, both in Poland and abroad, assumes the possibility of ruling about the occurrence of disorders like dyslexia among children and adolescents with epilepsy. How can we, therefore, explain the distinctness of the Polish reality against the background of other educational systems (e.g., the German) in which additional symptoms can be diagnosed despite neurological disease? And, consequently, is the undertaken problem only a "local," specifically Polish phenomenon? Maybe, it is an exclusively academic discussion, behind which there are no significant consequences for the patient? Or, perhaps, it is a much more serious problem than could have been expected at the beginning?

Answers to these questions are to be sought both in the laws introduced by the legislator and in the standards of conduct commonly approved by specialists 
engaged in psychological and pedagogical jurisdiction. Both of these sources use an interpretation of guidelines included in the International Statistical Classification of Diseases and Related Health Problems (commonly known as ICD10) (World Health Organization, 1992). According to this interpretation, there is no possibility of formulating an SpLDs diagnosis in children with epilepsy. It automatically crosses out the chance of obtaining the ruling about specific learning difficulties and, in consequence, it makes it impossible for the patient to receive effective and properly adjusted forms of therapy and educational support, including, for instance, exempting a student with deep dyslexia from the obligation to learn a foreign language, which is allowed under the Regulation of the Minister of National Education (Dz. U. [Legal Gazette] from 2007, No. 83, item 562). In the face of such a situation, there arises one fundamental question: does the "mistake" consist in the fact that the system of education of children with specific educational needs has been based on a medical classification that does not adhere to or, to be more specific, does not fully embrace, all the problems which ill children have to tackle, or is it rather a matter of a "mistake" in the interpretation, which consists in using the existing classification of diseases and disorders not to its full scope?

\section{SPECIFIC LEARNING DIFFICULTIES - CLASSIFICATION AND RULING}

The group of patients with SpLDs constitutes a rapidly growing number of children with the so-called special educational needs (Brzezińska et al., 2014). The incidence of the occurrence of difficulties in learning has been estimated to be in about $5-15 \%$ of school-age children (Lagae, 2008). Specific learning difficulties have been a problem with a rich history of studies, they have had many definitions and many different explanations (Firth, 1999, Snowling, 2001). Today, it is believed that SpLDs are a heterogeneous phenomenon with a neurobiological (neurological) basis, and that their occurrence causes learning disorders that, in the end, are perceived as an imbalance between the child's potential capabilities and its school achievements. Despite the long history of studies, the etiology of SpLDs still remains a matter of discussion. Among their causes scientists list both genetic and neuropsychological factors as well as socio-psychological and environmental ones (Peterson and Pennington, 2012). The ability to differentiate between the factors mentioned above and their various configurations can be helpful in distinguishing children with SpLDs from children who learn slower or are unwilling to learn. Thanks to the efforts of Professor Marta Bogdanowicz, Poland is at the top of European countries in which real actions for improving the quality of life of children with specific learning difficulties have been conducted for many years now (Bogdanowicz and Sayles, 2004). Prophylaxis and prevention (studies of the so-called dyslexia risk) (Bogdanowicz, 2011), social campaigns that increase the public awareness of problems of students with SpLDs, comprehensive therapeutic options and correct rulings, give an oppor- 
tunity for optimizing the functioning of the child at school, with the full observance and understanding of its problems (Rafał-Łuniewska, 2010). In this situation, the lack of a possibility to transfer these actions and expand them to yet another group of addressees, who in this case are children with epilepsy and co-occurring symptoms of SpLDs, seems to be irrational.

The diagnosis of children and adolescents suspected of having SpLDs is conducted by psycho-pedagogical out-patients clinics that issue rulings and opinions for schools and other educational institutions. Therefore, it lies within the competence of psycho-pedagogical units to recognize the symptoms and formulate a correct diagnosis and, in consequence, what seems to be most important, to define appropriate forms of learning and help for the given child. Appropriate are such forms of learning that take into consideration both the strong and weak sides of the child's development within its full spectrum.

The basic criterion tool on which the Polish system of ruling in the sphere of education of children and adolescents with difficulties in learning is built, is the medical classification ICD-10 (World Health Organization, 1992). In the case of SpLDs, this stipulates what follows: "These disorders consist in an impairment of normal patterns of acquiring scholastic skills from early stages of the development. They are not just a simple consequence of the lack of possibilities to learn or a sole effect of a mental handicap, traumas or brain diseases. F.81." This group of difficulties includes: Specific reading disorder (coded in the classification as F81.0), Specific spelling disorder (code F81.1), Specific disorder of arithmetical skills (code F.81.2), Mixed disorder of scholastic skills (code F81.3), Other developmental disorder of scholastic skills (code F81.8) and Other developmental disorders of scholastic skills (code F81.9). A detailed classification of the specific developmental disorders of scholastic skills has been presented in Table 1.

As Table 1 shows, SpLDs can be diagnosed only in individuals in the intellectual norm, under the condition that the observed symptoms do not have exclusively neurological causes (ibid.). Therefore, it seems that the occurrence of the SpLDs symptoms in patients with a neurological disease is treated as an effect of the disease per se. Due to the formal difficulties mentioned above (neurological disease), patients in the Polish education system with the diagnosis of epilepsy who also manifest SpLDs like, for instance, dyslexia, are in a difficult situation. Nevertheless, let us leave the formal difficulties aside for a moment.

\section{SPECIFIC LEARNING DIFFICULTIES AND EPILEPSY - A REVIEW OF STUDIES}

In the literature on the discussed disease, reports about the occurrence of SpLDs in this group of patients can be found for a number of years now (Stores, 1976). One of the wider studies on a representative group of patients was conducted 20 years ago by Schachter (Schachter, Galaburda and Ransil, 1993). On the basis of retrospective data, the author showed then that problems of the dyslexia type would occur four times more frequently in patients with epilepsy 
Table 1. The classification of specific developmental disorders of scholastic skills according to ICD-10

\section{F81 Specific developmental disorders of scholastic skills}

Disorders in which the normal patterns of skill acquisition are disturbed from the early stages of development. This is not simply a consequence of a lack of opportunity to learn, it is not solely a result of mental retardation, and it is not due to any form of acquired brain trauma or disease.

F81.0 Specific reading disorder

The main feature is a specific and significant impairment in the development of reading skills that is not solely accounted for by mental age, visual acuity problems, or inadequate schooling. Reading comprehension skill, reading word recognition, oral reading skill, and the performance of tasks requiring reading may all be affected. Spelling difficulties are frequently associated with specific reading disorder and often remain into adolescence even after some progress in reading has been made. Specific developmental disorders of reading are commonly preceded by a history of disorders in speech or language development. Associated emotional and behavioural disturbances are common during the school age period.

"Backward reading"

Developmental dyslexia

Excl.:

Specific reading retardation

alexia NOS (R48.0)

dyslexia NOS (R48.0)

reading difficulties secondary to emotional disorders (F93.-)

F81.1 Specific spelling disorder

The main feature is a specific and significant impairment in the development of spelling skills in the absence of a history of specific reading disorders, which is not solely accounted for by a low mental age, visual acuity problems, or inadequate schooling. The ability to spell orally and to write out words correctly are both affected.

Excl.: Specific spelling retardation (without reading disorder)

agraphia NOS (R48.8)

spelling difficulties:

- $\quad$ associated with a reading disorder (F81.0)

- due to inadequate teaching (Z55.8)

F81.2 Specific disorder of arithmetical skills

Involves a specific impairment in arithmetical skills that is not solely explicable on the basis of general mental retardation or of inadequate schooling. The deficit concerns mastery of basic computational skills of addition, subtraction, multiplication, and division rather than of the more abstract mathematical skills involved in algebra, trigonometry, geometry, or calculus.

Developmental:

- acalculia

- $\quad$ arithmetical disorder

Excl.:

- Gerstmann syndrome

acalculia NOS (R48.8)

arithmetical difficulties:

- $\quad$ associated with a reading or spelling disorder (F81.3)

- due to inadequate teaching (Z55.8)

F81.3 Mixed disorder of scholastic skills

An ill-defined residual category of disorders in which both arithmetical and reading or spelling skills are significantly impaired, but in which the disorder is not solely explicable in terms of general mental retardation or of inadequate schooling. It should be used for disorders meeting the criteria for both F81.2 and either F81.0 or F81.1.

Excl.:

specific:

- disorder of arithmetical skills (F81.2)

- $\quad$ reading disorder (F81.0)

- $\quad$ spelling disorder (F81.1)

F81.8 Other developmental disorders of scholastic skills

Developmental expressive writing disorder

F81.9 Developmental disorder of scholastic skills, unspecified

Knowledge acquisition disability NOS

Learning:

- disability NOS

- disorder NOS 
than in the control group, which consisted of patients with other neurological diagnoses (ibid.). Whereas, procedures of hemispherectomy conducted in patients with epilepsy, which were to decrease the number of epileptic seizures, constituted the basis of research into the phenomenon of dyslexia itself (Cummine et al., 2009). One of the contemporary examples of research into relationships between reading skills and epilepsy is the work of Vanasse and colleagues (Vanasse et al., 2005), in which the authors investigated the ability to read in 30 children with epilepsy (10 patients with temporal lobe epilepsy, 10 patients with frontal lobe epilepsy and 10 patients with unconsciousness seizures) and in healthy children. The results obtained by the researchers showed that in the investigated groups of patients with epilepsy the reading skills were on a lower level than in the group of healthy children. The results of the studies also indicate that the level of particular components of the reading ability differ in children with different epilepsy syndromes (ibid.). A review of publications on the co-occurrence of SpLDs and epilepsy has been presented in Table 2.

SpLDs can co-occur with epilepsy in three possible variants. In the first variant, the child develops the so-called dyslexia risk or developmental dyslexia before the onset of epileptic seizures (see the illustration of the problem on the example of a case described in Table 3). In the second option, children who were in the past diagnosed with and treated for epilepsy, after the treatment has been successfully completed, manifest difficulties typical of, for instance, dyslexia. The third variant pertains to people who simultaneously manifest difficulties of the SpLDs type and have been diagnosed with epilepsy. In practice, in the first of the described variants, the information about developing symptoms of SpLDs before the occurrence of epileptic seizures causes the diagnosis of dyslexia risk or developmental dyslexia to be revoked, despite the fact that the symptoms could have been observed earlier, whereas in the case of the second and the third option, it makes the diagnosis of disorders from the spectrum of SpLDs completely impossible. In all of the distinguished variants, an appropriate intervention and actions connected with therapy and providing support in learning are impossible. In many cases, such a situation has a much more negative effect on the functioning of children with epilepsy than the disease itself, especially if the disease has a mild character. Moreover, we should have in mind that there is yet another group of children and adolescents in the case of whom there occur both the symptoms of SpLDs and epilepsy, but the latter symptoms have not been diagnosed. This kind of situation can take place in patients with Rolandic epilepsy or with epilepsy with unconsciousness seizures, in the case of whom the period between the occurrence of the first visible epileptic seizures and the diagnosis and introduction of a pharmacological treatment is frequently very long (Pąchalska et al., 2012; Mirski et al., 2012). It is worthy to note that a good response to relative beta training, applied to regulate the dynamics of brain function in a patient with benign partial epilepsy with Rolandic Spikes (BPERS), associated with neuropsychiatric deficits resembling the symptoms of attention deficithyperactivity disorder (ADHD) (see: Pąchalska et al., 2012; Mirski et al., 2012). 
Table 2. Review of the literature on the co-occurrence of SpLDs and epilepsy

\begin{tabular}{|c|c|c|c|c|}
\hline Publication & $\begin{array}{l}\text { Type of } \\
\text { studies }\end{array}$ & $\begin{array}{l}\text { Number } \\
\text { of } \\
\text { patients }\end{array}$ & $\begin{array}{l}\text { Epilepsy } \\
\text { syndrome }\end{array}$ & $\begin{array}{l}\text { Conclusions } \\
\text { from the studies }\end{array}$ \\
\hline Temple (1984) & case studies & 1 & & - dyslexia \\
\hline $\begin{array}{l}\text { Schachter et al. } \\
\text { (1993) }\end{array}$ & $\begin{array}{l}\text { intergroup } \\
\text { comparisons }\end{array}$ & 200 & $\begin{array}{l}\text { Heterogeneous } \\
\text { group }\end{array}$ & $\begin{array}{l}\text { - taking into consideration their } \\
\text { life history, the patients with } \\
\text { epilepsy had dyslexia four } \\
\text { times more frequently than the } \\
\text { patients from the control group }\end{array}$ \\
\hline $\begin{array}{l}\text { Cumming et al. } \\
\qquad(2009)\end{array}$ & case studies & 2 & $\begin{array}{l}\text { Localization- } \\
\text { related epilepsy } \\
\text { - patients after the } \\
\text { procedure of } \\
\text { hemispherectomy } \\
\end{array}$ & \\
\hline $\begin{array}{l}\text { Papavasiliou et al. } \\
\text { (2005) }\end{array}$ & $\begin{array}{l}\text { intergroup } \\
\text { comparisons }\end{array}$ & 32 & Rolandic epilepsy & $\begin{array}{l}\text { - the patients with Rolandic } \\
\text { epilepsy manifested disorders } \\
\text { of the dyslexia type } \\
\text { - four patients had difficulties } \\
\text { of the dyslexia type before the } \\
\text { development of epilepsy }\end{array}$ \\
\hline $\begin{array}{l}\text { Bedoin et al. } \\
\qquad(2011)\end{array}$ & $\begin{array}{l}\text { intergroup } \\
\text { comparisons }\end{array}$ & 18 & Rolandic epilepsy & $\begin{array}{l}\text { - one case of deep dyslexia } \\
\text { - atypical lobe asymmetry for } \\
\text { phonological processes in } \\
\text { patients with Rolandic epilepsy }\end{array}$ \\
\hline $\begin{array}{c}\text { Canavese et al. } \\
(2007)\end{array}$ & case studies & 10 & Rolandic epilepsy & $\begin{array}{l}\text { - two cases of dyscalculia } \\
\text { - one case of dyslexia }\end{array}$ \\
\hline Mirski et al. 2014 & case study & 1 & Rolandic epilepsy & $\begin{array}{l}\text { neuromarker of rolandic } \\
\text { epilepsy with the use of } \\
\text { guantitative } \\
\text { electroencephalography } \\
\text { (qEEG) and event related } \\
\text { potentials (ERPs) } \\
\text { - atypical lobe asymmetry for } \\
\text { phonological processes in MRI } \\
\text { - cognitive dysfunction } \\
\text { (attention, dyslexia, dysgraphia, } \\
\text { dyscalculia) } \\
\text { - behavioral changes }\end{array}$ \\
\hline $\begin{array}{l}\text { Pąchalska et al. } \\
\text { (2012) }\end{array}$ & case study & 1 & Rolandic epilepsy & $\begin{array}{l}\text { - neuromarker of rolandic } \\
\text { epilepsy with the use of } \\
\text { guantitative } \\
\text { electroencephalography (qEEG) } \\
\text { and event related potentials } \\
\text { (ERPs) } \\
\text { - atypical lobe asymmetry for } \\
\text { phonological processes in MRI } \\
\text { - cognitive dysfunction } \\
\text { (attention, dyslexia, dysgraphia, } \\
\text { dyscalculia) } \\
\text { - behavioral changes }\end{array}$ \\
\hline $\begin{array}{l}\text { Vanasse et al. } \\
\qquad(2005)\end{array}$ & $\begin{array}{l}\text { intergroup } \\
\text { comparisons }\end{array}$ & 30 & $\begin{array}{l}10 \text { patients with } \\
\text { temporal lobe } \\
\text { epilepsy, } 10 \\
\text { patients with } \\
\text { frontal lobe } \\
\text { epilepsy and } 10 \\
\text { patients with } \\
\text { unconsciousness } \\
\text { seizures }\end{array}$ & $\begin{array}{l}\text { - lower level of reading skills in } \\
\text { the group of patients with } \\
\text { epilepsy in comparison to the } \\
\text { control group }\end{array}$ \\
\hline Chaix et al. (2006) & $\begin{array}{l}\text { intergroup } \\
\text { comparisons }\end{array}$ & 34 & $\begin{array}{l}10 \text { patients with } \\
\text { temporal lobe } \\
\text { epilepsy, } \\
12 \text { patients with } \\
\text { Rolandic epilepsy, } \\
12 \text { patients with } \\
\text { idiopathic epilepsy }\end{array}$ & $\begin{array}{l}\text { - reading difficulties dominated } \\
\text { in the group of patients with } \\
\text { temporal lobe epilepsy }\end{array}$ \\
\hline
\end{tabular}


Table 3. Illustration of the problem on the case of a 12-year-old boy

A child of a first uneventful pregnancy. Vaginal delivery took place on time. Apgar score=10. Psychomotor development of the child in the first months of life was normal. Milestones in the development up to 3 years of age were conducted in accordance with the standard. The boy constructed simple verbal expressions at 18 months of age. From preschool frequent infections began - mostly of the glue ear type. At 4 years of age a speech defect was revealed and corrected by a speech therapist. In the preschool period the child's difficulty in performing graphomotoric activities (problems with redrawing basic shapes) were also noticed. He avoided drawing and painting and also had problems with learning songs and poems by heart. However, despite the difficulties, in the parents and nursery teachers' evaluation, the boy was described as very "inquisitive" with a surprising knowledge about the world. At the age of 6 the boy started attending school. Due to considerable difficulties with learning letters he was sent to a district Psycho-Pedagogical outpatient clinic.

Psychological examination indicated the boy's above average intellectual ability and inharmonious course in the development of cognitive functions, including poor phonological processing skills, difficulty in learning simple patterns of sequential activities, difficulties with low motility and a decreased short-term memory process. The boy was qualified within the so-called groups of children at risk of dyslexia. He continued speech therapy and began specialized pedagogical treatment. Despite these actions his acquisition of reading skills and the comprehension of text was still below age norms.

The patient read letter by letter and had problems with phonology. Due to the risk of dyslexia, in accordance with the Polish educational system, the boy had to be retested at the age of 11. At the age of 8 he suffered from encephalitis of viral etiology. He started having complex partial seizures (disturbances of consciousness, smacking his lips, chewing, rubbing his hands and movements of searching).

After starting antiepileptic treatment (Valproic acid, Topiramate, Carbamazepine) the seizures had been controlled satisfactorily, their number decreased by $80 \%$. The boy was re-examined in a psychologicalpedagogical outpatient clinic at the age of 11 years 8 months. In the psychological study the boy's level of intelligence was in the range of above the norm for his age. The boy, however, was still experiencing difficulties in learning to read and write, and the errors he made were not different from those in the premorbid period.

Pedagogical study showed the slow pace of reading and writing, poor auditory differentiation (errors of the type of letter replacement), and the loss of orientation on a line or page while reading. In writing there were numerous orthographic errors including writing the words jointly and disjointedly and the omission of letters. $\mathrm{He}$ had significant problems with reading nonsense and unknown words aloud. Attention deficit was a new symptom which appeared after epileptic seizures and the administration of pharmacological treatment.

According to the educational legislation, despite the existing and persisting difficulties in acquiring academic skills, the patient was unable to obtain a decision on specific learning difficulties due to the diagnosis of epilepsy. In consequence the requirements were not adjusted to the boy's abilities and the appropriate educational system of specialized support was withheld.

Although epilepsy is undoubtedly a neurological disease, we should ask whether every diagnosis of epilepsy in a child really means discovering a sole factor, listed in the ICD-10 classification, that is responsible for the appearance of, for instance, difficulties in learning how to read, and which, at the same time, makes it impossible to diagnose, for example, developmental dyslexia? The complexity of the discussed disease, along with the variety of factors that condition the typical course of acquiring the ability to learn, results in a situation where a correct classification of the problems exhibited by patients is very difficult. For, many other factors have proved to have an influence on the course of the processes of acquiring scholastic skills by ill children. Among the main factors there are: 1) the pre-disease condition (e.g., the child's skills and abilities), 2) factors connected with the disease (e.g., the etiology and type of the epilepsy syndrome) (Aldenkamp et al., 2005), 3) the moment when the disease occurred in the context of the child's developmental processes, 4) the duration of the disease, 5) the immediate effect of epileptic activity (e.g., partial seizures vs. generalized, the occur- 
rence of status epilepticus or transient cognitive impairment) (Aldenkamp, 2004), 6) factors associated with the treatment: surgical and/or pharmacological (ljff and Aldenkamp, 2013; Sherman et al., 2003), 7) the absence from school connected with the occurrence of seizures (Aguiar et al., 2007), 8) the profile of cognitive deficits that appear in the course of the disease (Aldenkamp et al., 2005), 9) factors associated with the patient's socio-economical conditions (Fastenau et al., 2004). Of significant meaning for the appearance of school difficulties can also be psychiatric disorders that co-occur with epilepsy (depression, anxiety, or intensified symptoms of attention deficit hyperactivity disorder, commonly known as ADHD) (Reilly, Agnew and Neville, 2011). Another important factor is the availability of appropriate educational care, and teachers' attitude towards students with epilepsy and their awareness of the problems these students may experience (Bohac and Wodrich, 2013). Studies suggest that children and adolescents with epilepsy experience more frequently than their healthy peers difficulties in the realization of particular educational stages (for instance, due to their absence from school), they have to repeat a year or are transferred from the school (Aguiar et al., 2007). They are more frequently the recipients of different forms of development support, including the possibility of realizing their compulsory education in the form of individual classes or with lowered requirements and various other forms of support (e.g., helplines) (Berg et al., 2011).

\section{DISCUSSION}

The medical classification ICD-10 in force in Europe makes it impossible to formulate a simultaneous SpLDs diagnosis in patients with neurological diseases, even when it completely explains the appearance of learning difficulties symptoms (World Health Organization, 1992). This limitation seems to be understandable from the perspective of the necessity to distinguish between two different types of SpLDs etiology: either with neurodevelopmental disorders or with diseases of the nervous system as the main cause. In consequence of differentiating between the two types of etiologies, two different types of therapeutic procedures can also be distinguished: oriented at neuropsychological support and compensation of the development, and focused on neurological treatment, respectively. However, the practice of diagnosing shows that the above differentiations are not as clear as one might expect. For, applying precisely the guidelines included in ICD-10 we should consider whether diagnosing SpLDs in children with other neurological diseases than epilepsy is authorized. Observations suggest, however, that diagnosticians tend to approach in a less "rigid" manner diagnosing SpLDs in children and adolescents who suffer from, for instance, migraines with aura, tension-type headaches, tic disorders, Tourette's disorder or attention deficit hyperactivity disorders than in children with epilepsy, despite the fact that among the symptoms that co-occur with these diagnoses one can observe permanent or temporary disorders of higher mental functions (Debes et al., 2011; Greven et al., 2012; Mathuri et al., 2015; Riva et al., 2012). Also, we 
should not forget that SpLDs, due to the complexity of the development of learning abilities, have many etiologies, including ones about which we know nothing yet. Another source of problems in providing help to children with epilepsy and learning difficulties stems from the formal binding of particular forms of help with only one group of disorders - SpLDs, which results in the exclusion from the group of children with other diagnoses. In Poland, a particularly privileged group has been, for unknown reasons, the group of children with developmental dyslexia.

One possible method of solving the problem of providing help to individuals who suffer from epilepsy and/or other neurological diseases would be qualifying children for different forms of help mainly on the basis of symptomatology and not nosological diagnosis. In such a scenario, etiological hypotheses would only serve as auxiliary means, having rather a secondary meaning, and would be used for preparing a detailed plan of working with the child. We use the term 'etiological hypotheses', because etiology of neurodevelopmental disorders is still an issue that raises many questions and is, in the first place, difficult to be verified in practice in individual diagnoses. Our proposal is not innovative, it rather means going back to the roots - to the concept of functional systems as developed by Aleksander Łuria (1976). The central notion and starting point of diagnosis is in this concept a task that can be realized by means of different measures (mental functions and cerebral localizations). In this perspective, therapeutic help consists predominantly in the compensation of the limited (e.g., by a neurological disease) possibilities of realizing important tasks (e.g., learning).

Additionally, it seems that in the case of the discussed issue it is crucial to decide about the diagnosis of SpLDs on the basis of the time period during which the symptoms of specific learning difficulties appeared in context of the occurrence of neurological disorders. In a situation where they had appeared earlier than the symptoms of the neurological disease (with the obvious assumption that it causes disorders to the patient's intellectual functioning), it would be advisable to treat difficulties in learning as a form primary to the neurological disease. When specific learning difficulties appear in the course of a neurological disease, it is advisable to diagnose SpLDs as symptoms secondary to the main disease. Such a solution has been suggested in the very ICD-10 classification (World Health Organization, 1992), on the basis of which we can formulate a diagnosis of, for instance, reading difficulties that are an effect of a disease process or a treatment [e.g., dyslexia after the procedure of hemispherectomy (Cummine et al., 2009)]. In this case, there is a possibility of diagnosing either the so-called "Mild cognitive disorder" (coded in the classification as F.06.7) or "Dyslexia and other symbolic dysfunctions, not elsewhere classified" (code R48), while constructing the diagnosis we could actually use the notion of secondary dyslexia, secondary dyscalculia and so on. Possible diagnoses of specific learning difficulties in cases secondary to a neurological disease have been presented in Table 4. 
Table 4. Secondary disorders of the type of specific learning difficulties observed in the course of neurological diseases

\begin{tabular}{|l|}
\hline$[\ldots]$ \\
F06 Other mental disorders due to brain damage and dysfunction and to physical disease \\
Includes miscellaneous conditions causally related to brain disorder due to primary cerebral disease, to \\
systemic disease affecting the brain secondarily, to exogenous toxic substances or hormones, to endocrine \\
disorders, or to other somatic illnesses. \\
Excl.: \\
associated with: \\
delirium (F05.-) \\
dementia as classified in F00-F03 \\
resulting from the use of alcohol and other psychoactive substances (F10-F19) \\
\hline$[\ldots .]$. \\
F06.7 Mild cognitive disorder \\
A disorder characterized by impairment of memory, learning difficulties, and reduced ability to concentrate \\
on a task for more than brief periods. There is often a marked feeling of mental fatigue when mental tasks \\
are attempted, and new learning is found to be subjectively difficult even when objectively successful. None \\
of these symptoms is so severe that a diagnosis of either dementia (F00-F03) or delirium (F05.-) can be \\
made. This diagnosis should be made only in association with a specified physical disorder, and should not \\
be made in the presence of any of the mental or behavioural disorders classified to F10-F99. The disorder \\
may precede, accompany, or follow a wide variety of infections and physical disorders, both cerebral and \\
systemic, but direct evidence of cerebral involvement is not necessarily present. It can be differentiated \\
from postencephalitic syndrome (F07.1) and postconcussional syndrome (F07.2) by its different etiology, \\
more restricted range of generally milder symptoms, and usually shorter duration. \\
{$[\ldots]$} \\
\hline R48 Dyslexia and other symbolic dysfunctions, not elsewhere classified \\
Excl.: \\
specific developmental disorders of scholastic skills (F81.-) \\
R48.0 Dyslexia and alexia \\
R48.1 Agnosia \\
R48.2 Apraxia \\
R48.8 Other and unspecified symbolic dysfunctions \\
Acalculia \\
Agraphia
\end{tabular}

\section{CONCLUSIONS}

Observations and the analysis of studies leave no doubt that the co-occurrence with epilepsy of disorders of the specific learning difficulties type, and the poorer school achievements in children and adolescents associated with them, is possible (Pavlou and Gkampeta, 2011; Pąchalska et al 2012). Taking into account the fact that epilepsy is one of the most frequently occurring (up to $1 \%$ of children and adolescents), chronic neurological disease, and that its onset falls on the period of life from early childhood to adolescence, emotional, cognitive and social problems experienced by patients coincide, to a large extent, with school age (Berg, Jallon and Preux, 2013). Even if we assume that only a part of children and adolescents with epilepsy experience difficulties in learning, they still constitute a large group in need of educational help (Fastenau et al., 2008; Pąchalska et al., 2012; Kropotov et al 2014).

The school problems of patients with epilepsy pose an important challenge for education systems around the world. As the authors have tried to show in the present article, it seems justifiable to start a discussion and try to revise the solutions and procedures commonly acknowledged in Poland that are applied when 
symptoms of specific learning difficulties can be spotted in children and adolescents with epilepsy. The present work also points to the great and urgent need for research on relationships between the co-occurrence of SpLDs and other neurological diseases. It seems, both from the perspective of the current state of knowledge and clinical practice, that the most appropriate approach to the problem of specific learning difficulties in patients with epilepsy should in every case take into consideration the possibility of their co-occurrence and, depending on the time of the onset of the first symptoms of SpLDs in context of epilepsy, they could be classified either as primary (developmental) or secondary (acquired). For children with epilepsy constitute a group of individuals at particular risk of SpLDs, which has been confirmed by the works of Vanasse and colleagues (Vanasse et al., 2005), Papavasiliou and colleagues (Papavasiliou et al., 2005), or Chaix and colleagues (Chaix et al., 2006). Correctly classifying the difficulties experienced by patients makes it possible to introduce an efficient help system (e.g., different forms of psychological and pedagogical help available within the education system) and, at the same time, to reduce limitations and increase the patients' quality of life.

The cognitive deficits characteristic for cognitive and behavioral deficit in a child with BPERS may be unresponsive to antiepileptic treatment, but are reversible after a carefully selected neurotherapy program, combined with antiepileptic treatment. It should be stress that Event Related Potentials (ERPs) in the GO/NOGO task can be used to assess functional brain changes induced by neurotherapeutical programs (Pąchalska et al., 2012; Mirski et al., 2014).

In the case of the group of patients with difficulties in the realization of school education and other children whose intellectual abilities, despite suffering from a neurological condition, do not deviate from established norms, it might be worth considering the possibility of specialized education that would be based upon the knowledge of and familiarity with medical problems and their influence on the children's learning process.

\section{REFERENCES}

Aguiar, B. V., Guerreiro, M. M., McBrian, D., Montenegro, M. A. (2007). Seizure impact on the school attendance in children with epilepsy. Seizure, 16(8), 698-702. doi: 10.1016/j.seizure. 2007. 05.013

Aldenkamp, A. P., Arends, J. (2004). Effects of epileptiform EEG discharges on cognitive function: is the concept of "transient cognitive impairment" still valid? Epilepsy and Behaviour, 5 Suppl 1, 25-34.

Aldenkamp, A. P., Weber, B., Overweg-Plandsoen, W. C., Reijs, R., van Mil, S. (2005). Educational underachievement in children with epilepsy: a model to predict the effects of epilepsy on educational achievement. Journal of Child Neurology, 20(3), 175-180.

Bedoin, N., Ferragne, E., Lopez, C., Herbillon, V., De Bellescize, J., des Portes, V. (2011). Atypical hemispheric asymmetries for the processing of phonological features in children with rolandic epilepsy. Epilepsy and Behaviour, 21(1), 42-51. doi: 10.1016/j.yebeh.2011.02.026

Berg, A. T., Hesdorffer, D. C., Zelko, F. A. (2011). Special education participation in children with epilepsy: what does it reflect? Epilepsy and Behaviour, 22(2), 336-341. doi: 10.1016/j.yebeh. 2011.07.014

Berg, A. T., Jallon, P., Preux, P. M. (2013). The epidemiology of seizure disorders in infancy and childhood: definitions and classifications. Handbook of Clinical Neurology, 111, 391-398. doi: 10.1016/B978-0-444-52891-9.00043-9 
Berg, A. T., Langfitt, J. T., Testa, F. M., Levy, S. R., DiMario, F., Westerveld, M., Kulas, J. (2008). Global cognitive function in children with epilepsy: a community-based study. Epilepsia, 49(4), 608-614. doi: 10.1111/j.1528-1167.2007.01461.x

Bogdanowicz, M. (2011). Ryzyko dysleksji, dysortografii i dysgrafii : skala ryzyka dysleksji wraz z normami dla klas I i ll. Gdańsk: Harmonia Universalis.

Bogdanowicz, M., Sayles, H. A. (2004). Rights of dyslexic children in Europe. Gdańsk: Wydawnictwo Harmonia.

Bohac, G., Wodrich, D. L. (2013). A model-based approach to understanding school status of students with epilepsy. Epilepsy and Behaviour, 27(1), 4-8. doi: 10.1016/j.yebeh.2012.12.012

Brzezińska, A., Jabłoński, S., Ziółkowska, B. (2014). Specyficzne i specjalne potrzeby edukacyjne. Edukacja 2(127), 37-52.

Canavese, C., Rigardetto, R., Viano, V., Vittorini, R., Bassi, B., Pieri, I., Capizzi, G. (2007). Are dyslexia and dyscalculia associated with Rolandic epilepsy? A short report on ten Italian patients. Epileptic Disorders, 9(4), 432-436. doi: 10.1684/epd.2007.0138

Chaix, Y., Laguitton, V., Lauwers-Cances, V., Daquin, G., Cances, C., Demonet, J. F., Villeneuve, N. (2006). Reading abilities and cognitive functions of children with epilepsy: influence of epileptic syndrome. Brain Development, 28(2), 122-130. doi: 10.1016/j.braindev.2005.06.004

Cummine, J., Borowsky, R., Winder, F. S., \& Crossley, M. (2009). Basic reading skills and dyslexia: three decades following right versus left hemispherectomy for childhood-onset intractable epilepsy. [Case Reports Research Support, Non-U.S. Gov't]. Epilepsy and Behaviour, 15(4), 470-475. doi: 10.1016/j.yebeh.2009.05.018

Debes, N. M., Lange, T., Jessen, T. L., Hjalgrim, H., \& Skov, L. (2011). Performance on Wechsler intelligence scales in children with Tourette syndrome. European Journal of Paediatric Neurology, 15(2), 146-154. doi: 10.1016/j.ejpn.2010.07.007

Elger, C. E., Helmstaedter, C., Kurthen, M. (2004). Chronic epilepsy and cognition. Lancet Neurology, 3(11), 663-672. doi: 10.1016/S1474-4422(04)00906-8

Fastenau, P. S., Jianzhao, S., Dunn, D. W., Austin, J. K. (2008). Academic underachievement among children with epilepsy: proportion exceeding psychometric criteria for learning disability and associated risk factors. Journal of Learning Disabilities, 41(3), 195-207. doi: 10.1177/ 0022219408317548

Fastenau, P. S., Shen, J., Dunn, D. W., Perkins, S. M., Hermann, B. P., Austin, J. K. (2004). Neuropsychological predictors of academic underachievement in pediatric epilepsy: moderating roles of demographic, seizure, and psychosocial variables. Epilepsia, 45(10), 1261-1272. doi: 10.1111/j.0013-9580.2004.15204.x

Fournier, N. M., Calverley, K. L., Wagner, J. P., Poock, J. L., Crossley, M. (2008). Impaired social cognition 30 years after hemispherectomy for intractable epilepsy: the importance of the right hemisphere in complex social functioning. [Case Reports Research Support, Non-U.S. Gov't]. Epilepsy and Behaviour, 12(3), 460-471. doi: 10.1016/j.yebeh.2007.12.009

Frith,U. (1999). Paradoxes in the definition of dyslexia. Dyslexia, 5, 192-214.

Greven, C. U., Rijsdijk, F. V., Asherson, P., Plomin, R. (2012). A longitudinal twin study on the association between ADHD symptoms and reading. Journal of Child Psychology and Psychiatry, 53(3), 234-242. doi: 10.1111/j.1469-7610.2011.02445.x

Ijff, D. M., Aldenkamp, A. P. (2013). Cognitive side-effects of antiepileptic drugs in children. Handbook of Clinical Neurology, 111, 707-718. doi: 10.1016/B978-0-444-52891-9.00073-7.

Kropotov J.D., Pachalska M.,Mueller A.(2014) New neurotechnologies for the diagnosis and modulation of brain dysfunctions. Health Psychology Report 2(2): 73-82.

Lagae, L. (2008). Learning disabilities: definitions, epidemiology, diagnosis, and intervention strategies. Pediatric Clinics of North America, 55(6), 1259-1268, vii. doi: 10.1016/j.pcl.2008.08.001

Łuria, A. (1976). Podstawy neuropsychologii. Warszawa: PZWL.

Mathur, V. A., Khan, S. A., Keaser, M. L., Hubbard, C. S., Goyal, M., Seminowicz, D. A. (2015). Altered cognition-related brain activity and interactions with acute pain in migraine. Neurolmage: Clinical, 7, 347-358. doi: 10.1016/j.nicl.2015.01.003.

Mirski A., Pachalska M., Mirska N., Jauer Niworowska O., Gryglicka K., Kropotov luD. (2014) An evaluation of personalized neurofeedback training for Rolandic epilepsy: a case study. Acta Neuropsychologica. 12 (3): 271-287. 
Papavasiliou, A., Mattheou, D., Bazigou, H., Kotsalis, C., Paraskevoulakos, E. (2005). Written language skills in children with benign childhood epilepsy with centrotemporal spikes. Epilepsy and Behaviour, 6(1), 50-58. doi: 10.1016/j.yebeh.2004.09.008.

Pavlou, E., Gkampeta, A. (2011). Learning disorders in children with epilepsy. Child's Nervous System, 27(3), 373-379. doi: 10.1007/s00381-010-1321-9.

Pąchalska M., Kropotov I.D., Mańko G., Lipowska M., Rasmus A, Łukaszewska B., Bogdanowicz M., Mirski A. (2012) Evaluation of a neurotherapy program for a child with ADHD with Benign Partial Epilepsy with Rolandic Spikes (BPERS) using event-related potentials. Medical Science Monitor. 18(11) CS 94-104.

Peterson, R. L., Pennington, B. F. (2012). Developmental dyslexia. Lancet, 379(9830), 1997-2007. doi: 10.1016/S0140-6736(12)60198-6.

Rafał-Łuniewska, J. (2010). Strategia działań wobec ucznia z grupy ryzyka dysleksji. Warszawa. Wydawnictwo ORE.

Reilly, C., Agnew, R., Neville, B. G. (2011). Depression and anxiety in childhood epilepsy: a review. Seizure, 20(8), 589-597. doi: 10.1016/j.seizure.2011.06.004.

Reilly, C. J. (2011). Attention deficit hyperactivity disorder (ADHD) in childhood epilepsy. Res Dev Disabil, 32(3), 883-893. doi: 10.1016/j.ridd.2011.01.019

Riva, D., Usilla, A., Aggio, F., Vago, C., Treccani, C., Bulgheroni, S. (2012). Attention in children and adolescents with headache. Headache, 52(3), 374-384. doi: 10.1111/j.1526-4610.2011.02033.x

Rozporządzenie Ministra Edukacji Narodowej z dnia 30 kwietnia 2007 r. w sprawie warunków i sposobu oceniania, klasyfikowania promowania uczniów $i$ słuchaczy oraz przeprowadzania sprawdzianów i egzaminów w szkołach publicznych (Dz.U. 2007, poz. 562).

Rozporządzenie Ministra Edukacji Narodowej z dnia 17 listopada 2010r. (z późn. zm.) w sprawie warunków organizowania kształcenia, wychowania i opieki dla dzieci i młodzieży niepełnosprawnych oraz niedostosowanych społecznie w przedszkolach, szkołach i oddziałach ogólnodostępnych lub integracyjnych (Dz.U. Nr 228, poz. 1490).

Schachter, S. C., Galaburda, A. M., Ransil, B. J. (1993). Associations of dyslexia with epilepsy, handedness, and gender. Annals of the New York Academy of Sciences, 682, 402-403.

Sherman, E., Slick, D. J., Connolly, M. B., Steinbok, P., Martin, R., Strauss, E., Farrell, K. (2003). Reexamining the effects of epilepsy surgery on IQ in children: use of regression-based change scores. Journal of the International Neuropsychological Society, 9(6), 879-886.

Snowling, M. J. (2001). Dyslexia. Oxford: Blackwell Publishers.

Stores, G. (1976). The investigation and management of school children with epilepsy. Public Health, 90(4), 171-177.

Temple, C. M. (1984). Surface dyslexia in a child with epilepsy. [Case Reports Research Support, Non-U.S. Gov't]. Neuropsychologia, 22(5), 569-576.

Turner, W. A. (1907). Epilepsy, a study of the idiopathic disease. London: Macmillan.

Vanasse, C. M., Beland, R., Carmant, L., Lassonde, M. (2005). Impact of childhood epilepsy on reading and phonological processing abilities. Epilepsy and Behaviour, 7(2), 288-296. doi: 10.1016/j.yebeh.2005.05.008

World Health Organization (1992). The ICD-10 classification of mental and behavioural disorders: clinical descriptions and diagnostic guidelines. Geneva: WHO.

\section{Address for correspondence:}

Izabela Kaczmarek

The Department and Clinic of Developmental Neurology,

The Poznan University of Medical Science,

Przybyszewskiego 49, 60-355 Poznan

e-mail: isab@poczta.onet.pl 